OPEN ACCESS

Edited by:

Przemyslaw B. Kowalczuk, Norwegian University of Science and Technology, Norway

Reviewed by:

Lei Xie,

University of Alberta, Canada Guangyuan Xie,

China University of Mining and Technology, China

*Correspondence:

Leming Ou

olmpaper@csu.edu.cn

Specialty section:

This article was submitted to Physical Chemistry and Chemical

Physics,

a section of the journal

Frontiers in Chemistry

Received: 25 November 2019 Accepted: 13 March 2020

Published: 28 April 2020

Citation:

Zeng G, Ou L, Zhang $W$ and Zhu Y (2020) Effects of Sodium Alginate on the Flotation Separation of Molybdenite From Chalcopyrite Using Kerosene as Collector.

Front. Chem. 8:242.

doi: 10.3389/fchem.2020.00242

\section{Effects of Sodium Alginate on the Flotation Separation of Molybdenite From Chalcopyrite Using Kerosene as Collector}

\author{
Guangsheng Zeng ${ }^{1}$, Leming Ou ${ }^{2 *}$, Wencai Zhang ${ }^{3}$ and Yuteng Zhu ${ }^{2}$ \\ ${ }^{1}$ College of Chemistry and Chemical Engineering, Central South University, Changsha, China, ${ }^{2}$ School of Minerals \\ Processing and Bioengineering, Central South University, Changsha, China, ${ }^{3}$ Department of Mining and Minerals \\ Engineering, Virginia Polytechnic and State University, Blacksburg, VA, United States
}

In this paper, the effect of sodium alginate (SA) on the flotation separation of molybdenite $\left(\mathrm{MoS}_{2}\right)$ from chalcopyrite using kerosene as collector was systematically investigated. The results of single-mineral micro-flotation tests indicated that SA exhibited strong depression on chalcopyrite flotation while it imposed no impact on the floatability of molybdenite. However, in the chalcopyrite-molybdenite mixed-mineral flotation system, the presence of chalcopyrite significantly increased the depressing effect of SA on molybdenite flotation, leading to a considerable reduction in the flotation selectivity. The negative impact of chalcopyrite on the performance of SA in molybdenite flotation was eliminated by adding a certain dosage of kerosene prior to SA. A concentrate containing $53.43 \%$ of molybdenum (Mo) was obtained at $76.90 \%$ of recovery using 19 $\mathrm{mg} / \mathrm{L}$ kerosene and $40 \mathrm{mg} / \mathrm{L} \mathrm{SA}$ at $\mathrm{pH}$ 5.4. Zeta potential measurements indicated that the adsorption of SA on chalcopyrite surfaces was stronger than that on molybdenite surfaces, which agreed with the single-mineral flotation test results. The adsorption of SA on chalcopyrite was further confirmed to be chemisorption by Fourier-transform infrared spectroscopy (FTIR) spectra analyses. When $\mathrm{Cu}^{2+}$ appeared in solution, the flotation of molybdenite was strongly depressed by SA. Mechanism analyses indicated that more active sites were generated on molybdenite surfaces after the addition of $\mathrm{Cu}^{2+}$, thus promoting the adsorption of SA.

Keywords: molybdenite, chalcopyrite, sodium alginate, $\mathrm{Cu}^{2+}$-activation, flotation

\section{INTRODUCTION}

Molybdenite $\left(\mathrm{MoS}_{2}\right)$ is the primary source of molybdenum (Mo), and approximately half of the Mo production is obtained from copper $(\mathrm{Cu})$-Mo sulfides, mainly porphyry $\mathrm{Cu}$ deposits (Ansari and Pawlik, 2007; Song et al., 2012; Hirajima et al., 2014). At present, the flotation separation of $\mathrm{Cu}$ minerals and Mo minerals in this type of ore is normally achieved by selectively depressing the $\mathrm{Cu}$ sulfide minerals using various inorganic inhibitors. Sulfide is one of the most widely used Cu sulfide inhibitors in practical flotation processes (Pearse, 2005; Yin et al., 2010; Mehrabani et al., 2011; Zhao et al., 2018). However, the characteristics of high dosage and toxicity of inorganic inhibitors adversely affect the surrounding environment. Therefore, the development and application of more environment-friendly and cost-efficient inhibitors are crucial (Yin et al., 2017; Suyantara et al., 2018; Yuan et al., 2019a,b). 
Sodium alginate (SA) is a natural non-toxic anionic polysaccharide extracted from various species of brown algae comprised of $1 \rightarrow 4$ linked $\beta$-D-mannuronic acid $(M)$ and its C-5 epimer $\alpha$-L-guluronic acid (G) (Wang and Peng, 2014). It has been extensively applied in the fields of medical, health, biology, food, etc. (Lin et al., 2005; Pawar and Edgar, 2012; Hu et al., 2017; Su et al., 2017; Li et al., 2019). The molecular structure of SA is shown in Figure 1. Its molecular structure contains a large number of hydroxyl $(-\mathrm{OH})$ and carboxyl (-COO) groups, and the gelling reaction of SA with divalent cations can occur easily in solution (Zhu et al., 2003; Liu et al., 2008; Yu et al., 2017). Based on the properties of SA described above, SA was considered to be a potential alternative to conventional inorganic inhibitors. The feasibility of using SA as a flotation inhibitor has been tested for various minerals. For instance, SA was used as an inhibitor of molybdenite using amyl xanthate as collector in chalcopyrite flotation (Chen et al., 2018) and as an inhibitor of galena using ammonium dibutyl dithiophosphate as collector in chalcopyrite (Chen et al., 2019) and as an inhibitor to separate the scheelite from calcite and fluorite (Chen et al., 2017). However, the effects of SA on the flotation performances of chalcopyrite and molybdenite using kerosene as collector have not been reported yet. Therefore, in this paper, SA was utilized as a depressant to separate the molybdenite from chalcopyrite using kerosene as the collector. The adsorption behaviors of SA on the mineral surfaces were studied by adsorption measurements, zeta potential measurements, and Fourier-transform infrared spectroscopy (FTIR) spectra analyses.

\section{MATERIALS AND METHODS}

\section{Mineral Samples and Reagents}

Molybdenite and chalcopyrite samples used for this study were obtained from Tibet and Yunnan, China, respectively. Highgrade mineral crystals were manually picked out and pulverized to a top size of $1 \mathrm{~mm}$ using a laboratory roll crusher and a ceramic ball mill. The product was dry-sieved with standard screens to acquire the $-74+38-\mu \mathrm{m}$ and $-38-\mu \mathrm{m}$ fractions. The former fraction was used for micro-flotation tests and adsorption measurements. A portion of the latter fraction was further ground to minus $2 \mu \mathrm{m}$ for zeta potential measurements and FTIR analyses. Based on the X-ray diffraction (XRD) results shown in Figure 2, the purity of molybdenite and chalcopyrite was $95.68 \%$ and $98.23 \%$, respectively.
SA was supplied by Enoson Biotechnology Co., Ltd., Wuhan, China. A stock solution of SA ( $0.04 \%$ by weight) was prepared by dispersing a required amount of $\mathrm{SA}$ in deionized water with highspeed stirring. Kerosene and $\mathrm{CuCl}_{2}$ were both purchased from Tianjin Kermil Chemical Reagents Development Centre, Tianjin, China. Hydrochloric acid $(\mathrm{HCl})$ and sodium hydroxide $(\mathrm{NaOH})$ were used as $\mathrm{pH}$ regulators and methyl isobutyl carbinol (MIBC) was used as frother. All reagents were analytical pure except for SA which was food grade. Deionized water was used throughout this study.

\section{Micro-Flotation Tests}

All the flotation tests were conducted in an XFG-1600-type laboratory flotation machine. For single-mineral flotation tests, $2.0 \mathrm{~g}$ pure mineral sample was first placed in a beaker of $50-\mathrm{ml}$ capacity together with $30 \mathrm{ml}$ deionized water. Ultrasonic cleaning of 5 min was applied to the suspension to remove the oxidized substances on the mineral surface, after which the supernatant was decanted and the mineral particles were washed into a plexiglass flotation cell of $40-\mathrm{ml}$ capacity with proper amount of deionized water. The pulp was stirred for $1 \mathrm{~min}$ at 1,902 $\mathrm{rpm}$ to ensure thorough mixing, after which the $\mathrm{pH}$ regulators, depressant (if needed), collector, and frother were sequentially

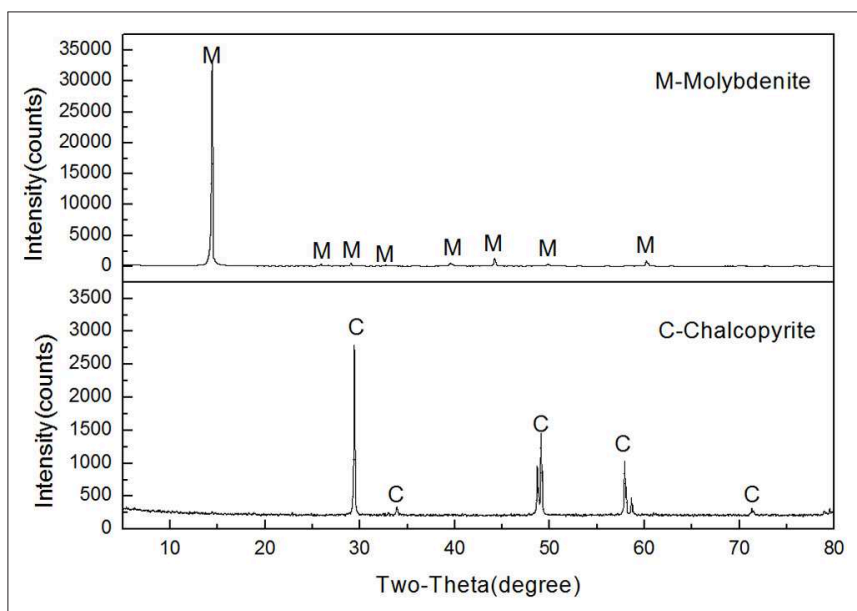

FIGURE 2 |X-ray diffraction (XRD) spectra of the chalcopyrite and molybdenite samples.

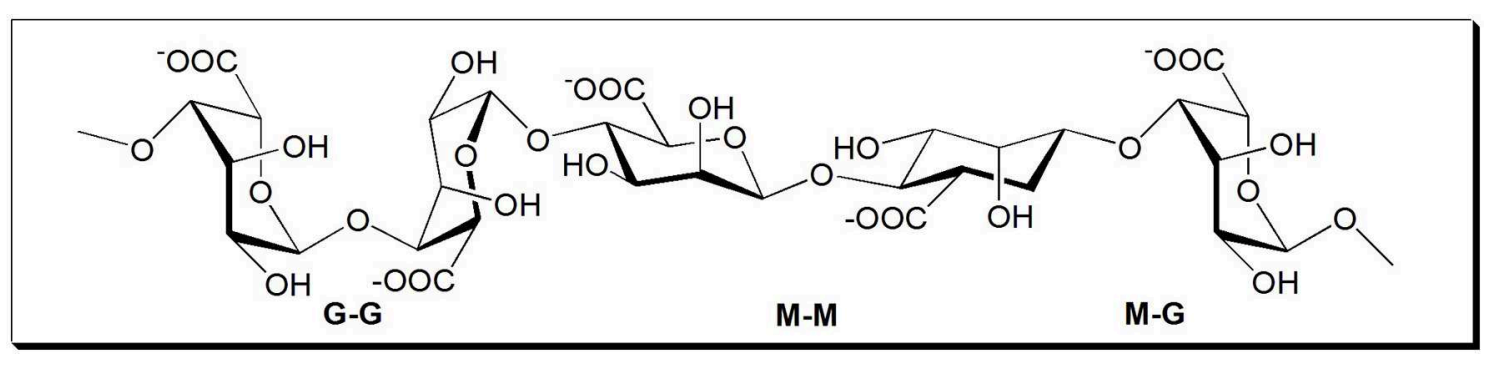

FIGURE 1 | Molecular structure of sodium alginate (SA). 
added into the suspension. The pulp was conditioned for $3 \mathrm{~min}$ after each addition except for the frother $(1 \mathrm{~min})$. Flotation was conducted for a total period of $3 \mathrm{~min}$ for each test. After flotation, the concentrates (froth product) and tailings (in-tank product) were collected, filtered, dried and weighed. The recovery was calculated based on the weight distribution of mineral particles between the two products. Each single-mineral flotation test was repeated at least three times. The average values were reported in this study. Standard deviations were also calculated and presented as error bars.

For the mixed binary minerals flotation tests, the mass ratio of chalcopyrite and molybdenite was $2: 1$ (2.0 g chalcopyrite $+1.0 \mathrm{~g}$ molybdenite). The flotation procedures are similar to those used for the single-mineral flotation tests except that two different reagent addition sequences were tested, namely, kerosene prior to SA and SA prior to kerosene. The concentrates and tailings were assayed for $\mathrm{Cu}$ and Mo. The recovery of molybdenite and chalcopyrite was calculated based on the grades of $\mathrm{Cu}$ and $\mathrm{Mo}$ in the concentrates and tailings.

\section{Adsorption Measurements}

The adsorption of SA on both the original and $\mathrm{Cu}^{2+}$-treated molybdenite was measured as a function of $\mathrm{pH}$ using a TOCL machine supplied by Shimadzu, Kyoto, Japan. The detailed experimental procedures are as follows. First, $2.0 \mathrm{~g}$ of mineral samples were added to $40-\mathrm{ml}$ aqueous solutions in the presence or absence of $15 \mathrm{mg} / \mathrm{L} \mathrm{Cu}^{2+}$ followed by $30 \mathrm{~min}$ of conditioning. Then, the obtained suspensions were adjusted to the desired $\mathrm{pH}$ by adding hydrochloric acid and/or sodium hydroxide solutions, after which $40 \mathrm{mg} / \mathrm{L}$ SA was added into the suspensions followed by another $30 \mathrm{~min}$ of conditioning. The resultant suspensions were filtered, and subsequently the filtrate was centrifuged to remove residual particles under 9,000 rpm for $10 \mathrm{~min}$. Finally, $15 \mathrm{ml}$ supernatant of the centrifuged filtrate was collected for measuring the total organic carbon (TOC) concentration. The adsorption efficiency $(\varepsilon)$ was calculated by the following equation:

$$
\varepsilon=\frac{T_{0}-T_{1}}{T_{0}} \times 100 \%
$$

where $T_{0}$ represents the TOC concentration of freshly prepared SA solution of $40 \mathrm{mg} / \mathrm{L} ; T_{1}$ means the TOC concentration of the supernatant obtained from the adsorption tests.

\section{Zeta Potential Measurements}

Zeta potentials of the molybdenite and chalcopyrite particles were measured using a JS94H micro electrophoresis instrument (Shanghai Zhongchen Digital Technic Apparatus Co., Shanghai, China) under the room temperature of $25^{\circ} \mathrm{C} . \mathrm{KNO}_{3}$ solution of $1 \times 10^{-3} \mathrm{~mol} / \mathrm{L}$ was used as a supporting electrolyte. For each measurement, $20 \mathrm{mg}$ pure mineral $(-2 \mu \mathrm{m})$ was dispersed in $40 \mathrm{ml}$ of the electrolyte, and the suspension was magnetically stirred for $2 \mathrm{~min}$ after $\mathrm{pH}$ adjustment. Then, flotation reagents of desired dosages were added per the abovementioned reagent schemes. After standing for $5 \mathrm{~min}$, the supernatant was collected for zeta potential measurement. The measurement under each reagent condition was conducted at least three times, and the average values were accepted as the final results.

\section{FTIR Spectroscopy Analyses}

FTIR analyses in this study were performed using a 740FT-IR instrument (Nicolet Co., MA, USA) with the diffuse reflection approach (30 scans, resolution $2 \mathrm{~cm}^{-1}$ ) under room temperature. Spectra were collected in the absorption band range of 400 to $4,000 \mathrm{~cm}^{-1}$. Tested samples were prepared by adding $1.0 \mathrm{~g}$ pure mineral particles $(-2 \mu \mathrm{m})$ into $40 \mathrm{ml}$ deionized water with a desired reagent scheme at $\mathrm{pH}$ 5.4. After conditioning for $30 \mathrm{~min}$, the suspension was filtered and the filter cake was washed with deionized water of $\mathrm{pH} 5.4$ for three times. Then, the filter cake was dried in a vacuum oven at $30^{\circ} \mathrm{C}$. After the moisture got completely evaporated, the dry solid of $1 \mathrm{mg}$ was mixed with $100 \mathrm{mg}$ spectroscopic grade potassium bromide (KBr), and the mixture was used for the analysis.

\section{RESULTS AND DISCUSSIONS}

\section{Micro-Flotation Results}

\section{Single-Mineral Flotation Experiment Results}

Figure 3 shows the effect of SA dosage on the flotation performance of molybdenite and chalcopyrite when using $2 \mathrm{mg} / \mathrm{L}$ kerosene as collector at $\mathrm{pH}$ around 5.4. It can be seen from the figure that chalcopyrite recovery was $<5 \%$ when the dosage of SA exceeded $40 \mathrm{mg} / \mathrm{L}$. Interestingly, high recoveries (nearly $90 \%$ ) of molybdenite were maintained over the investigated SA dosage, indicating that SA imposed a minimal effect on the floatability of molybdenite. Therefore, the efficient separation of molybdenite from chalcopyrite is likely to be achieved by using SA and kerosene as depressant and collector, respectively.

The flotation recoveries of molybdenite and chalcopyrite as a function of $\mathrm{pH}$ in the absence and presence of SA are shown in Figure 4. The recovery of molybdenite changed slightly at the entire $\mathrm{pH}$ range with the addition of $40 \mathrm{mg} / \mathrm{L} \mathrm{SA}$, suggesting that SA barely influenced the molybdenite floatability. However, the recovery of chalcopyrite dropped significantly at $\mathrm{pH}$ 3-9 when

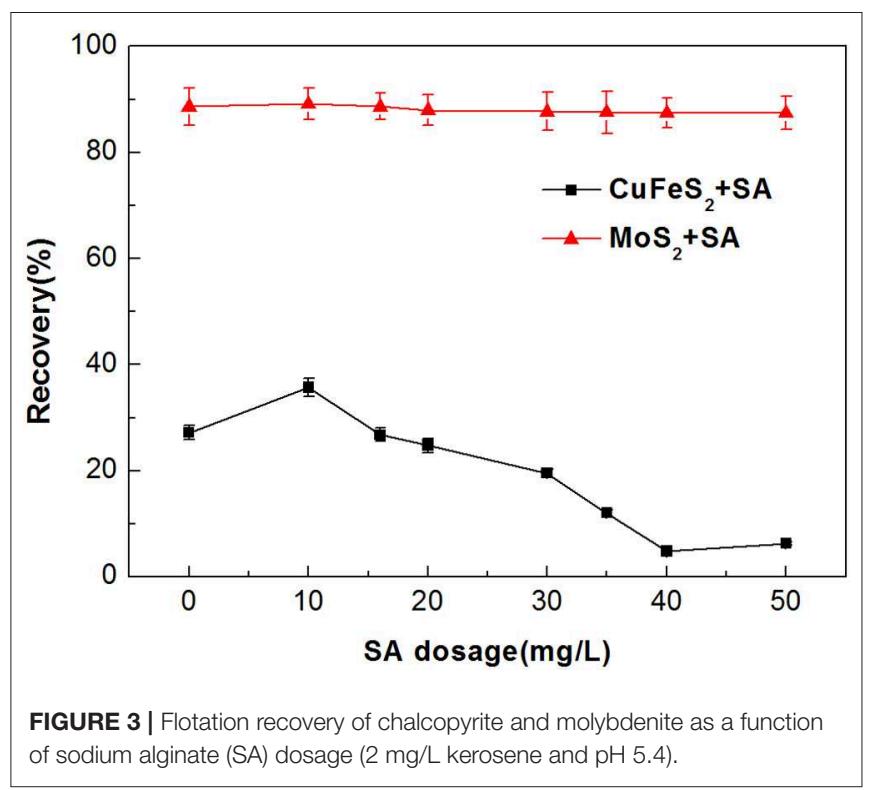


$40 \mathrm{mg} / \mathrm{L} \mathrm{SA}$ was added. Therefore, the optimum $\mathrm{pH}$ range for the separation of molybdenite from chalcopyrite was 3-9.

\section{Mixed-Mineral Micro-Flotation Results}

The aforementioned single-mineral flotation test results indicated that the efficient separation of molybdenite from chalcopyrite could be achieved by using SA as an inhibitor in the $\mathrm{pH}$ range of 3-9. When different minerals simultaneously appear in a solution, surface properties of the minerals can be greatly impacted by each other, resulting in changes in their affinities toward reagents (Jin et al., 2018; Tian et al., 2018). This can potentially reduce the selectivity of flotation reagents (Liu et al., 2016; Bicak et al., 2018; Feng et al., 2018). Therefore, flotation tests of mixed minerals (chalcopyrite plus molybdenite) were conducted to further investigate the selective inhibition performance of SA. The flotation results of a mixed-mineral system (the mass ratio of chalcopyrite to molybdenite equals 2:1) in the presence of $40 \mathrm{mg} / \mathrm{L} \mathrm{SA}$ under $\mathrm{pH} 5.4$ are presented in Table 1.

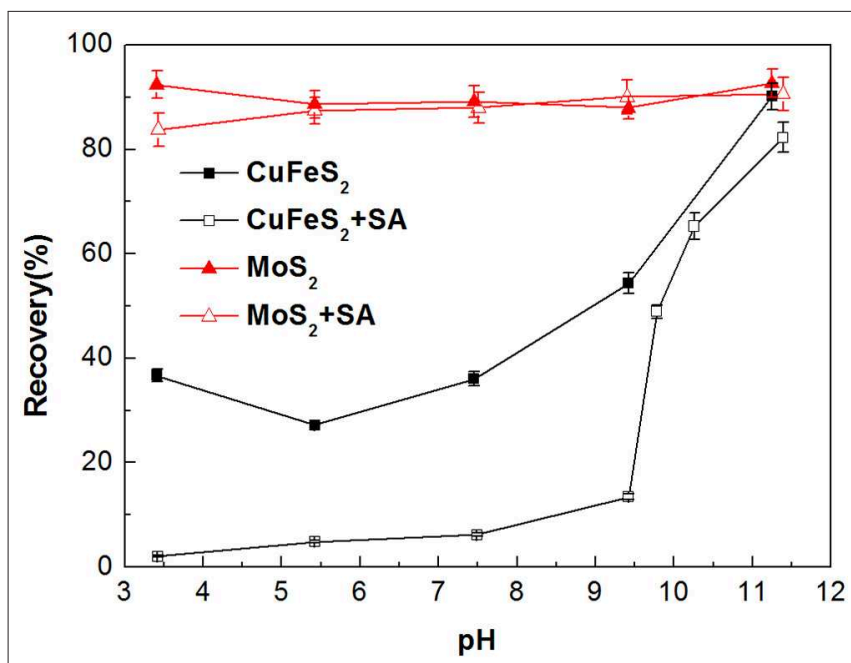

FIGURE 4 | Flotation recovery of chalcopyrite and molybdenite as a function of $\mathrm{pH}$ with and without sodium alginate (SA) (40 mg/L SA and $2 \mathrm{mg} / \mathrm{L}$ kerosene).
When SA was added prior to kerosene of $2 \mathrm{mg} / \mathrm{L}$ and $19 \mathrm{mg} / \mathrm{L}$, the concentrate $\mathrm{Cu}$ grades were 21.64 and $20.24 \%$, respectively, indicating a weak selectivity of SA in the mixed-mineral system. Meanwhile, the recovery of Mo in tailing were $64.03 \%$ for 2 $\mathrm{mg} / \mathrm{L}$ kerosene and $40.17 \%$ for $19 \mathrm{mg} / \mathrm{L}$ kerosene. Therefore, SA showed an inhibitory effect on molybdenite in the presence of chalcopyrite.

In order to eliminate the adverse effect of chalcopyrite on the flotation performance of SA, the effect of reagent scheme on the flotation results of chalcopyrite-molybdenite mixed systems was investigated. As shown in Table 1, a concentrate with Mo grade of $53.43 \%$ and recovery of $76.90 \%$ was acquired when kerosene was added before SA. This indicated that the addition of kerosene prior to SA could eliminate the adverse effect of chalcopyrite on the depressing effect of SA on molybdenite. Wie and Fuerstenau (1974) reported that adsorption of dextrin was reduced when molybdenite was coated with a layer of non-polar oil. This agrees with the findings from this study.

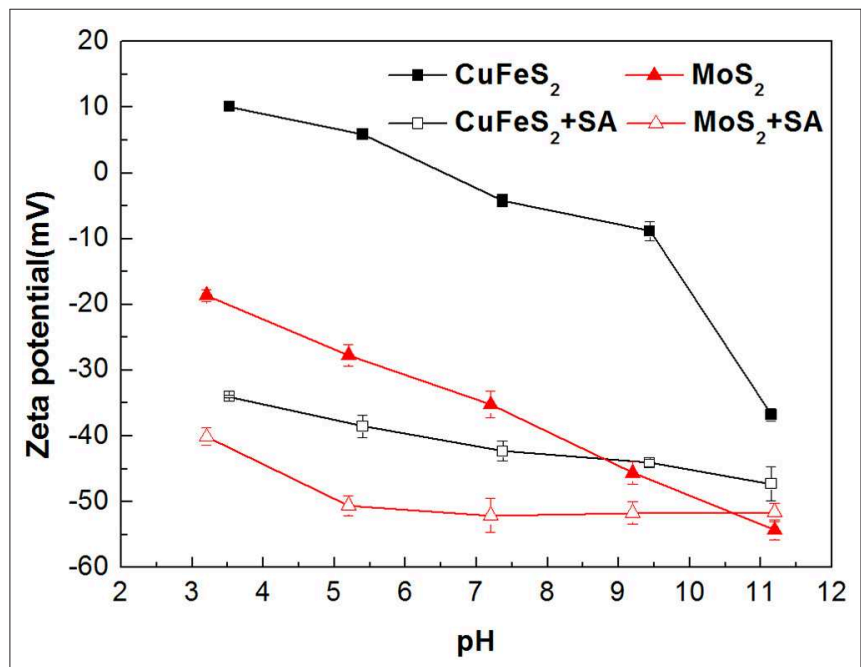

FIGURE 5 | The zeta potentials of chalcopyrite and molybdenite before and after conditioning with sodium alginate (SA) at varied $\mathrm{pH}$ ( $40 \mathrm{mg} / \mathrm{L} \mathrm{SA}$ and 2 $\mathrm{mg} / \mathrm{L}$ kerosene).

TABLE 1 | The separation of chalcopyrite and molybdenite mixture [ $40 \mathrm{mg} / \mathrm{L}$ sodium alginate (SA) and pH 5.4].

\begin{tabular}{|c|c|c|c|c|c|c|}
\hline Test conditions & & Products & Cu grade/\% & Mo grade/\% & Cu recovery/\% & Mo recovery/\% \\
\hline \multirow[t]{3}{*}{ SA prior to kerosene } & Kerosene dosage: & Concentrate & 21.64 & 28.98 & 23.42 & 35.97 \\
\hline & & Feed & 21.93 & 19.12 & 100 & 100 \\
\hline & Kerosene dosage: & Concentrate & 20.24 & 29.13 & 36.52 & 59.83 \\
\hline \multirow[t]{3}{*}{ kerosene prior to SA } & Kerosene dosage: & Concentrate & 4.55 & 53.43 & 5.78 & 76.90 \\
\hline & 19 mg/L & Tailing & 29.08 & 6.29 & 94.22 & 23.10 \\
\hline & & Feed & 22.17 & 19.57 & 100.00 & 100.00 \\
\hline
\end{tabular}




\section{Zeta Potential Measurement Results}

Zeta potentials of chalcopyrite and molybdenite as a function of $\mathrm{pH}$ are presented in Figure 5. It can be observed that remarkable negative shifts occurred in the zeta potentials of chalcopyrite and molybdenite when SA was added alone. Moreover, the shift for chalcopyrite was larger than the molybdenite, suggesting that SA adsorbed more strongly on the chalcopyrite surface relative to the molybdenite at the tested $\mathrm{pH}$ range. This can be explained by the fact that more negative charges occur on the molybdenite surface relative to chalcopyrite (Reyes-Bozo et al., 2015; Castro et al., 2016; Han et al., 2019; Yang et al., 2019), resulting in a stronger electrostatic repulsion between molybdenite and SA (anionic agents). Moreover, metal cations dissolved from the chalcopyrite surface could also contribute to the higher adsorption of SA (Ikumapayi et al., 2012). It is noteworthy that when $\mathrm{pH}$ exceeded 9.5, the zeta potential difference of raw and SA-conditioned chalcopyrite decreased, which corresponded to the steep rise of chalcopyrite recovery (Figure 4).

\section{Fourier-Transform Infrared Spectra}

Figure 6 presents the FTIR spectra of chalcopyrite and molybdenite before and after treatment with $40 \mathrm{mg} / \mathrm{L} \mathrm{SA}$ at $\mathrm{pH}$ 5.4. The peaks at 1,609 and $1,424 \mathrm{~cm}^{-1}$ of the $S A$ spectrum shown in Figure 6A were due to the stretching bands of -COO- (Rath et al., 2000; Chen et al., 2017, 2018), and the peak at $1,026 \mathrm{~cm}^{-1}$ originated from the stretching vibration of $\mathrm{C}-\mathrm{O}-\mathrm{C}$. As shown in Figure 6B, after conditioning with $\mathrm{SA}$, new peaks at 1,697 and $1,465 \mathrm{~cm}^{-1}$ occurred in the spectrum of chalcopyrite, which were shifted significantly compared to the corresponding peaks that present in the spectrum of SA (i.e., 1,609 and 1,424 $\mathrm{cm}^{-1}$ ). This proved that SA was chemically adsorbed on chalcopyrite surfaces and probably in the form of SA-Cu chelate, which has been reported in prior studies (Zhu et al., 2003; Liu et al., 2008). It is interesting to note that the spectrum of molybdenite treated by SA was barely changed relative to the raw specimen. Therefore, the adsorption of SA on molybdenite was negligible.

\section{Interaction Mechanisms of Chalcopyrite on the Sodium Alginate Performance in Molybdenite Flotation \\ The Effect of Sodium Alginate on the Flotation of $\mathrm{Cu}^{2+}$-Treated Molybdenite}

Metal ions dissolved from minerals may impose an adverse impact on the selectivity of flotation collector and depressant (Zhang et al., 2017; Zhang and Honaker, 2018). Dissolution of $\mathrm{Cu}^{2+}$ from the chalcopyrite surface is inevitable in the flotation separation of molybdenite from chalcopyrite (Zhao et al., 2018; Yang et al., 2019). Therefore, the effect of $\mathrm{Cu}^{2+}$ on the flotation performance of molybdenite was evaluated in the presence and absence of SA at $\mathrm{pH}$ around 5.4. As shown in Figure 7, when $\mathrm{Cu}^{2+}$ concentration varied from 0 to $25 \mathrm{mg} / \mathrm{L}$, the recovery of molybdenite decreased significantly in the presence of $40 \mathrm{mg} / \mathrm{L}$

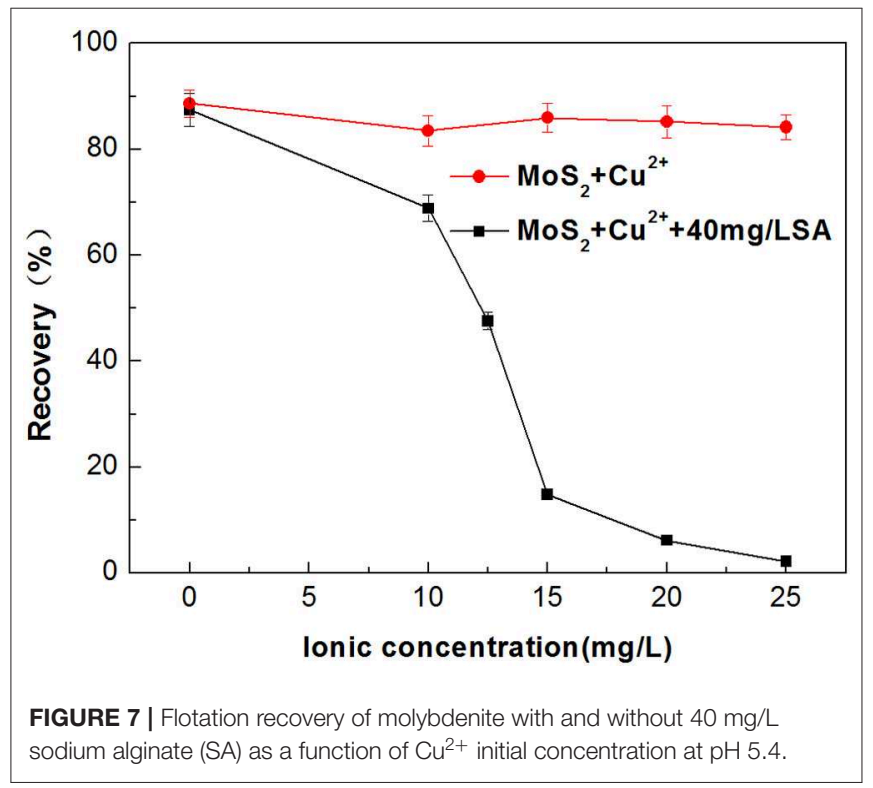

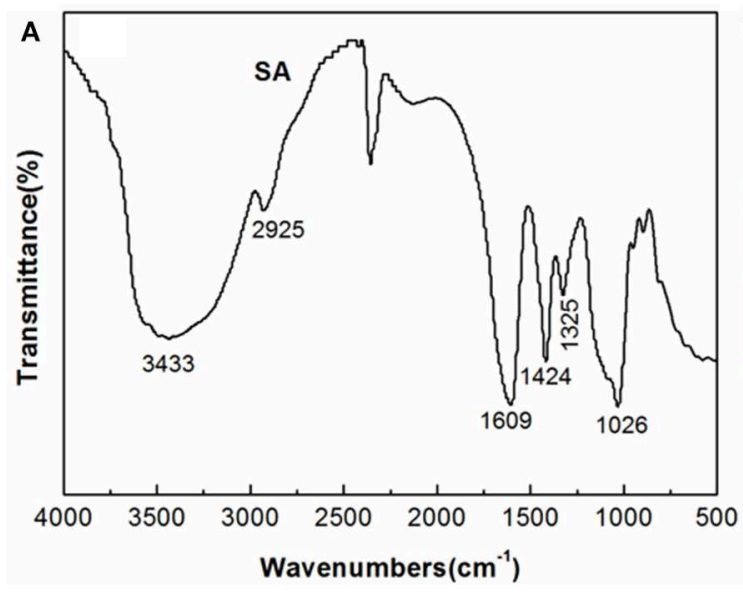

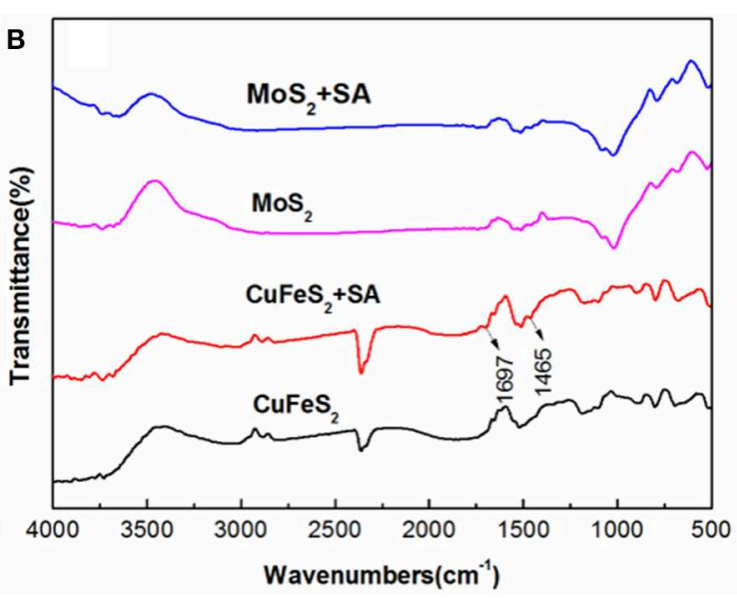

FIGURE 6 | Fourier-transform infrared spectroscopy (FTIR) spectra of (A) sodium alginate (SA), (B) chalcopyrite and molybdenite (the SA treatment was performed by conditioning with $40 \mathrm{mg} / \mathrm{L} \mathrm{SA}$ at $\mathrm{pH}$ 5.4). 


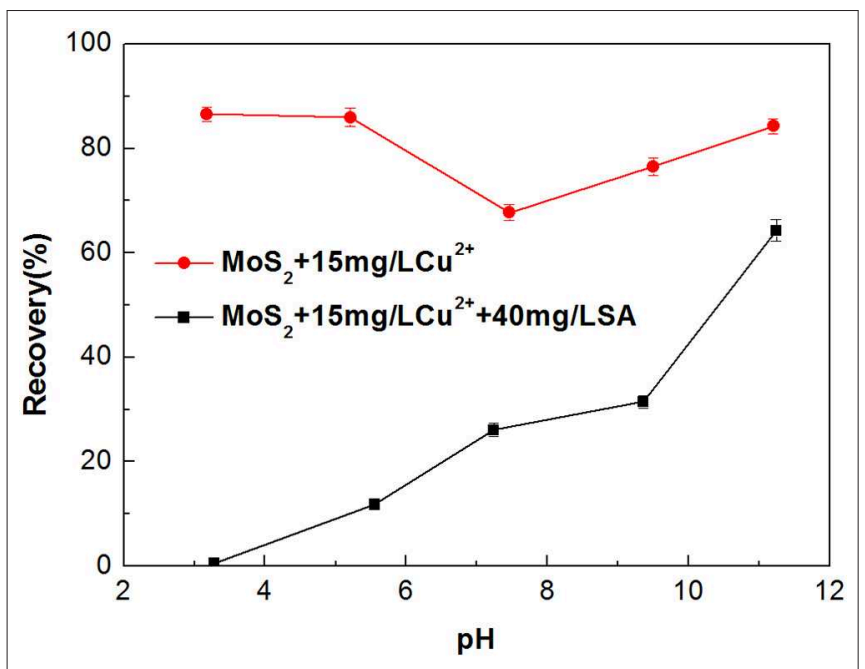

FIGURE 8 | Flotation recovery of molybdenite with and without $40 \mathrm{mg} / \mathrm{L}$ sodium alginate $(\mathrm{SA})$ as a function of $\mathrm{pH}$ in the presence of $15 \mathrm{mg} / \mathrm{L} \mathrm{Cu}^{2+}$.

SA. Furthermore, the depressing effect of SA on molybdenite flotation was largely dependent on $\mathrm{pH}$, and stronger inhibition occurred under acidic conditions (Figure 8).

\section{Adsorption Characteristics of Sodium Alginate on $\mathrm{Cu}^{2+}$-Treated Molybdenite}

The impact of $\mathrm{Cu}^{2+}$ on the adsorption characteristics of SA on the molybdenite surfaces is shown in Figure 9. In the absence of $\mathrm{Cu}^{2+}$, much stronger adsorption occurred at relatively low $\mathrm{pH}$, which can be explained by the formation of alginic acid that is insoluble under acidic conditions (Wang, 2007). When $\mathrm{Cu}^{2+}$ was added, the adsorption of SA on the molybdenite surface was increased significantly throughout the studied $\mathrm{pH}$ range. This is likely due to the increased amount of adsorption sites on the molybdenite surface provided by Cu species (Yang et al., 2019).

\section{Zeta Potentials of $\mathrm{Cu}^{2+}$-Treated Molybdenite With and Without Sodium Alginate}

Zeta potentials of molybdenite in the presence and absence of $\mathrm{Cu}^{2+}$ with $40 \mathrm{mg} / \mathrm{L}$ SA were measured at different $\mathrm{pH}$, and the results are presented in Figure 10. In the whole tested $\mathrm{pH}$ range, the raw molybdenite particles carried negative charges, and the zeta potential gradually decreased with the increase in $\mathrm{pH}$, which agreed well with prior studies (Zhao et al., 2018). When the particles were dispersed in $\mathrm{Cu}^{2+}$ solution of $15 \mathrm{mg} / \mathrm{L}$, the zeta potential of molybdenite increased and the trend curve was similar to that of Yang et al. (2019). According to their study, at $\mathrm{pH}$ lower than 5.4, the slightly positive shift of the molybdenite surface potential was due to a small amount of $\mathrm{Cu}^{2+}$ and $\mathrm{Cu}(\mathrm{OH})^{+}$being adsorbed on the molybdenite surface which offset the partially negative charge. The sharp rise in the range of $\mathrm{pH} 5.4$ to 9.5 was due to an increased amount of cupric species adsorbed and/or precipitated on the molybdenite surface. When $40 \mathrm{mg} / \mathrm{L}$ SA together with $15 \mathrm{mg} / \mathrm{L} \mathrm{Cu}^{2+}$ appeared in the solution, the zeta potential of molybdenite was decreased, which likely resulted from the adsorption of negatively charged alginate ions (Wang and Yang, 2014). Meanwhile, as the $\mathrm{pH}$ increased,

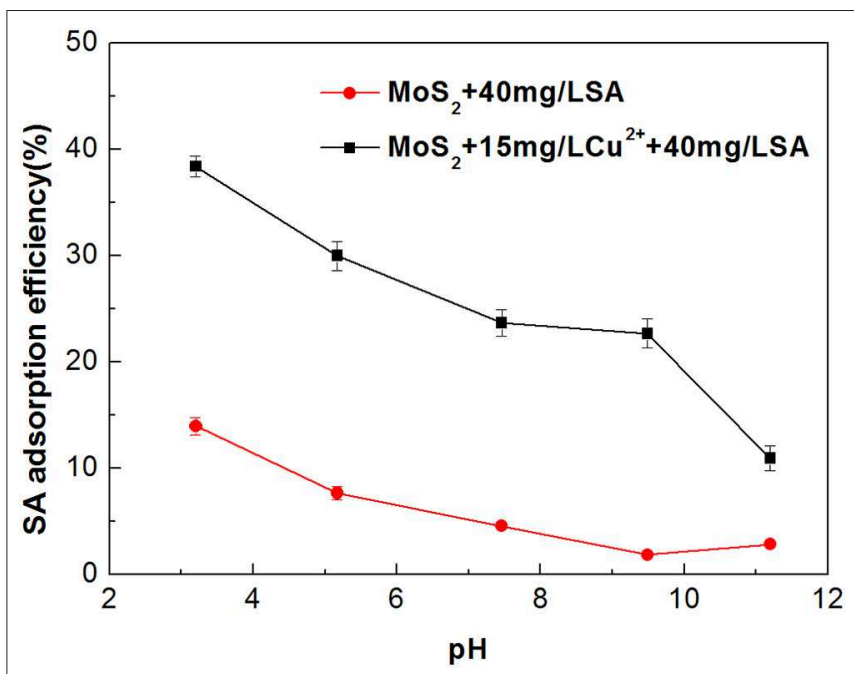

FIGURE 9 | Adsorption efficiency of sodium alginate (SA) on molybdenite surfaces with and without $15 \mathrm{mg} / \mathrm{L} \mathrm{Cu}^{2+}$ as a function of $\mathrm{pH}$.

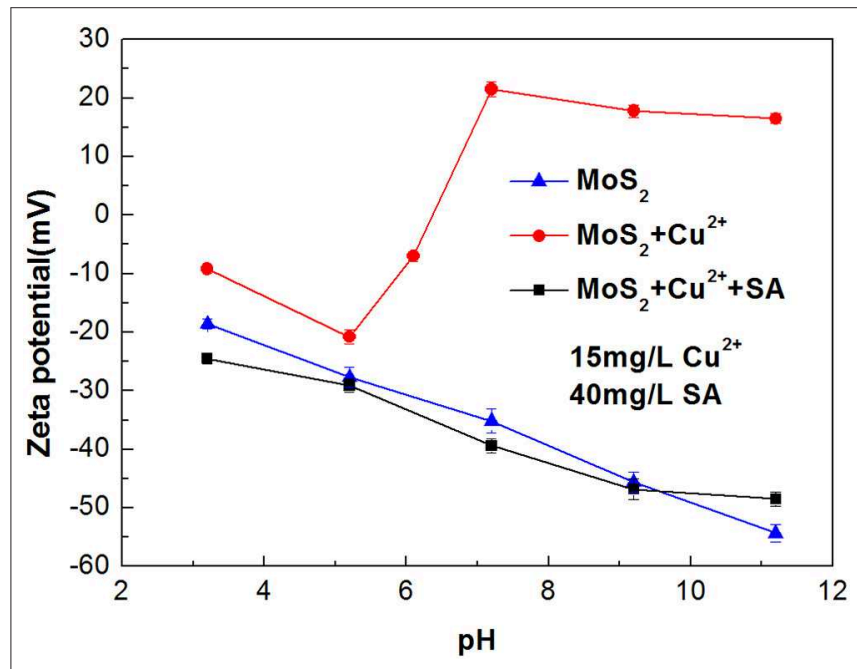

FIGURE 10 | Zeta potentials of molybdenite at varied $\mathrm{pH}$.

chelation between SA and cupric species in the solution was also promoted (Zhu et al., 2003), which partially led to the reduction of SA adsorption on molybdenite surfaces (Figure 7). At $\mathrm{pH}$ higher than $9.5, \mathrm{Cu}(\mathrm{OH})_{2(\mathrm{~s})}$ was dominant $\mathrm{Cu}$ species and the amount of $\mathrm{Cu}(\mathrm{OH})_{3}^{-}$and $\mathrm{Cu}(\mathrm{OH})_{4}^{2-}$ also gradually increased. As a result, the depressing effect of SA on molybdenite was further weakened due to enhanced electrostatic repulsion.

\section{Fourier-Transform Infrared Spectroscopy Spectra of $\mathrm{Cu}^{2+}$-Treated Molybdenite With and Without Sodium Alginate}

In order to further study the effect of $\mathrm{Cu}^{2+}$ on the depressing effect of SA on molybdenite, the IR spectra of molybdenite treated by $\mathrm{Cu}^{2+}, \mathrm{Cu}^{2+}+\mathrm{SA}$ were measured and the results are presented in Figure 11. For molybdenite treated by $\mathrm{Cu}^{2+}$ and $\mathrm{SA}$, new absorption bands at 1,612,1,562, and $1,425 \mathrm{~cm}^{-1}$ were observed 
and the new bands corresponded to the stretching vibration of COO- in SA, indicating the adsorption of SA on the molybdenite surface. The remarkable shift of the absorption band of -COOfrom 1,609 to $1,562 \mathrm{~cm}^{-1}$ demonstrated that partial chemical adsorption of SA occurred on the molybdenite surface.

Based on the results of the flotation tests and mechanism studies, a possible adsorption model was proposed to explain the depressing effect of chalcopyrite on the molybdenite flotation in the presence of $\mathrm{SA}$ at $\mathrm{pH} 5.4$ (Figure 12). At $\mathrm{pH} 5.4, \mathrm{Cu}$ ions occurring as $\mathrm{Cu}^{2+}$ and $\mathrm{Cu}(\mathrm{OH})^{+}$adsorbed on the molybdenite surface. Meanwhile, SA existed in the form of alginic acid (a little) and alginate ions (dominantly), and the adsorption of SA on the molybdenite surface occurred by chelating with $\mathrm{Cu}$ species via the -COO- and -OH. The electrostatic attraction between the negative group - $\mathrm{COO}$ - and the $\mathrm{Cu}$ species also contributed to the adsorption of SA. The promotion of SA adsorption by $\mathrm{Cu}^{2+}$ resulted in the depression of molybdenite flotation.

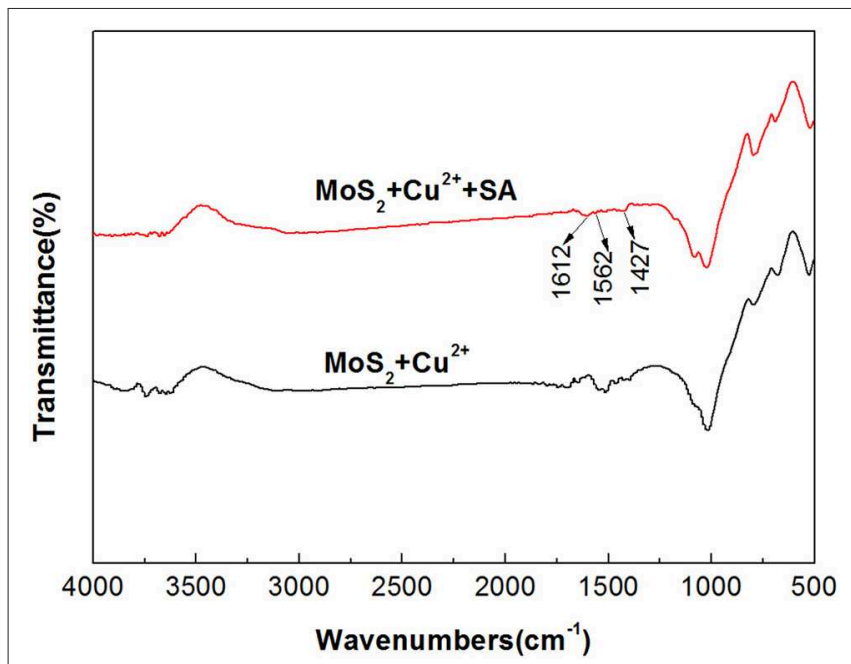

FIGURE 11 | Fourier-transform infrared spectroscopy (FTIR) spectra of molybdenite with and without treatment of $40 \mathrm{mg} / \mathrm{L}$ sodium alginate $(\mathrm{SA})$ in the presence of $15 \mathrm{mg} / \mathrm{L} \mathrm{Cu}^{2+}$ at $\mathrm{pH} 5.4$.

\section{CONCLUSIONS}

In this paper, interaction mechanisms of SA in the flotation separation of molybdenite from chalcopyrite were evaluated by micro-flotation tests, adsorption measurements, zeta potential measurements, and FTIR spectrum analyses. Single-mineral flotation tests showed that selective flotation separation of chalcopyrite and molybdenite could be achieved using SA as a depressant for the chalcopyrite. However, in the chalcopyritemolybdenite mixed-mineral flotation system, the presence of chalcopyrite significantly increased the depressing effect of SA on the molybdenite floatability, reducing the selectivity of the separation. It is interesting to note that the addition of a certain dosage of kerosene prior to SA could restore the molybdenite floatability in the mixed-mineral flotation system. Given the findings of the adsorption tests, zeta potential measurements, and FTIR analyses, it was concluded that SA chemically adsorbed on the surface of chalcopyrite, thus causing a considerable decrease in its floatability. Moreover, strong adsorption of $\mathrm{SA}$ on the $\mathrm{Cu}^{2+}$-treated molybdenite surfaces also occurred in forms of electrostatic attraction and chelation. Therefore, the negative impact of SA on molybdenite flotation in the mixed-mineral system was due to the dissolution of $\mathrm{Cu}$ ions from the chalcopyrite surfaces which re-adsorbed onto the molybdenite surfaces and played as active sites for SA adsorption.

\section{DATA AVAILABILITY STATEMENT}

All datasets generated for this study are included in the article/supplementary material.

\section{AUTHOR CONTRIBUTIONS}

GZ and LO conceived the research, designed the tests, and analyzed the data. GZ, WZ, and YZ wrote and revised the manuscript.
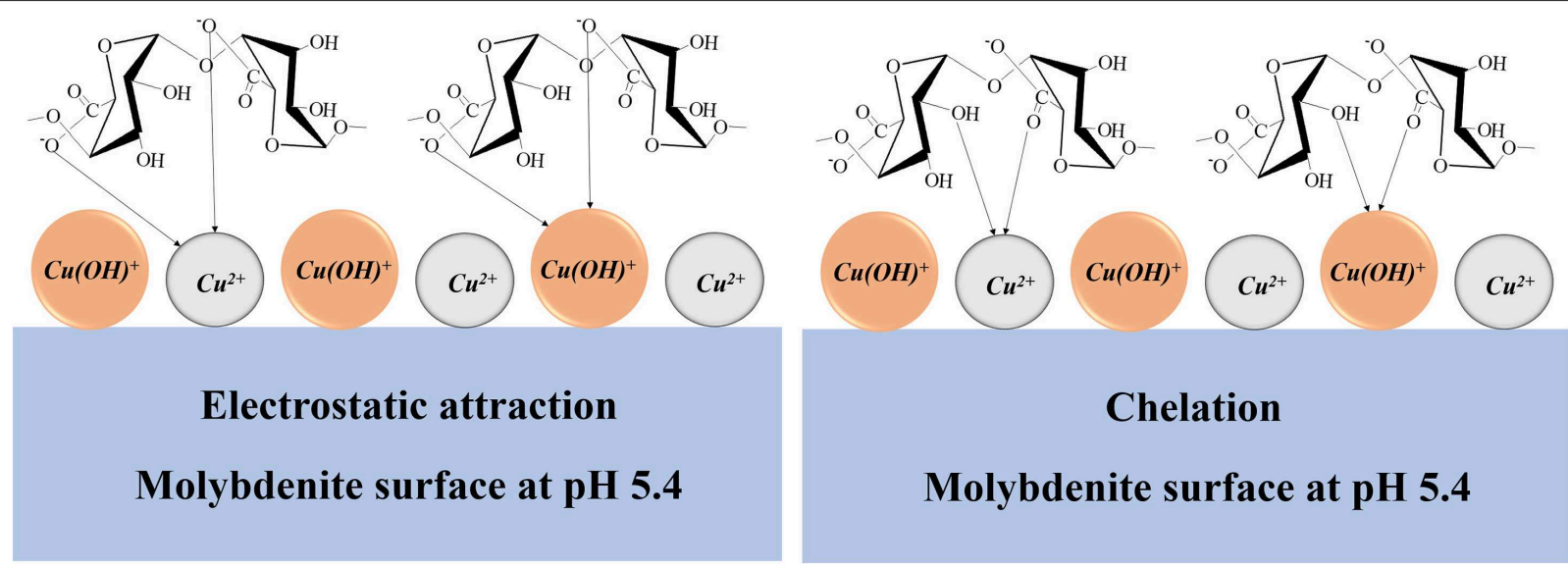

FIGURE 12 | Schematic diagram of influence mechanism of chalcopyrite on the performance of sodium alginate (SA) in molybdenite flotation at pH 5.4. 


\section{FUNDING}

This work was financially supported by the Fundamental Research Funds for the Central Universities of Central

\section{REFERENCES}

Ansari, A., and Pawlik, M. (2007). Floatability of chalcopyrite and molybdenite in the presence of lignosulfonates. Part II. Hallimond tube flotation. Miner. Eng. 20, 609-616. doi: 10.1016/j.mineng.2006.12.008

Bicak, O., Ozturk, Y., Ozdemir, E., and Ekmekci, Z. (2018). Modelling effects of dissolved ions in process water on flotation performance. Miner. Eng. 128, 84-91. doi: 10.1016/j.mineng.2018.08.031

Castro, S., Lopez-Valdivieso, A., and Laskowski, J. S. (2016). Review of the flotation of molybdenite. Part I: Surface properties and floatability. Int. J. Miner. Process. 148, 48-58. doi: 10.1016/j.minpro.2016.01.003

Chen, W., Chen, T., Bu, X., Chen, F., Ding, Y., Zhang, C., et al. (2019). The selective flotation of chalcopyrite against galena using alginate as a depressant. Miner. Eng. 141:105848. doi: 10.1016/j.mineng.2019. 105848

Chen, W., Feng, Q., Zhang, G., Yang, Q., and Zhang, C. (2017). The effect of sodium alginate on the flotation separation of scheelite from calcite and fluorite. Miner. Eng. 113, 1-7. doi: 10.1016/j.mineng.2017. 07.016

Chen, Z., Gu, G., Li, S., Wang, C., and Zhu, R. (2018). The effect of seaweed glue in the separation of copper-molybdenum sulphide ore by flotation. Minerals 8 , 1-15. doi: $10.3390 / \mathrm{min} 8020041$

Feng, Q., Wen, S., Zhao, W., and Chen, Y. (2018). Effect of calcium ions on adsorption of sodium oleate onto cassiterite and quartz surfaces and implications for their flotation separation. Sep. Purif. Technol. 200, 300-306. doi: 10.1016/j.seppur.2018.02.048

Han, G., Wen, S., Wang, H., and Feng, Q. (2019). Effect of starch on surface properties of pyrite and chalcopyrite and its response to flotation separation at low alkalinity. Miner. Eng. 143:106015. doi: 10.1016/j.mineng.2019. 106015

Hirajima, T., Mori, M., Ichikawa, O., Sasaki, K., Miki, H., Farahat, M., et al. (2014). Selective flotation of chalcopyrite and molybdenite with plasma pre-treatment. Miner. Eng. 66, 102-111. doi: 10.1016/j.mineng.2014.07.011

Hu, Y., Mao, A. S., Desai, R. M., Wang, H., Weitz, D. A., and Mooney, D. J. (2017). Controlled self-assembly of alginate microgels by rapidly binding molecule pairs. Lab Chip 17, 2481-2490. doi: 10.1039/C7LC00500H

Ikumapayi, F., Makitalo, M., Johansson, B., and Rao, K. H. (2012). Recycling of process water in sulphide flotation: effect of calcium and sulphate ions on flotation of galena. Miner. Eng. 39, 77-88. doi: 10.1016/j.mineng.2012. 07.016

Jin, S., Shi, Q., Li, Q., Ou, L., and Ouyang, K. (2018). Effect of calcium ionic concentrations on the adsorption of carboxymethyl cellulose onto talc surface: flotation, adsorption and AFM imaging study. Powder Technol. 331, 155-161. doi: 10.1016/j.powtec.2018.03.014

Li, Q., Lan, H., and Zhao, Z. (2019). Protection effect of sodium alginate against heat-induced structural changes of lactoferrin molecules at neutral pH. Lwt 99, 513-518. doi: 10.1016/j.lwt.2018.10.019

Lin, Y. H., Liang, H. F., Chung, C. K., Chen, M. C., and Sung, H. W. (2005). Physically crosslinked alginate/N,O-carboxymethyl chitosan hydrogels with calcium for oral delivery of protein drugs. Biomaterials 26, 2105-2113. doi: 10.1016/j.biomaterials.2004.06.011

Liu, C., Feng, Q., Zhang, G., Ma, W., Meng, Q., and Chen, Y. (2016). Effects of lead ions on the flotation of hemimorphite using sodium oleate. Miner. Eng. 89, 163-167. doi: 10.1016/j.mineng.2016.02.002

Liu, X., Yu, W., Wang, W., Xiong, Y., Ma, X., and Yuan, Q. (2008). Polyelectrolyte microcapsules prepared by alginate and chitosan for biomedical application. Prog. Chem. 20, 126-139.

Mehrabani, J. V., Mousavi, S. M., and Noaparast, M. (2011). Evaluation of the replacement of $\mathrm{NaCN}$ with Acidithiobacillus ferrooxidans in the flotation
South University (No. 2018zzts075) and the Key Laboratory of Hunan Province for Clean and Efficient Utilization of Strategic Calcium-containing Mineral Resources (No. 2018TP1002). of high-pyrite, low-grade lead-zinc ore. Sep. Purif. Technol. 80, 202-208. doi: 10.1016/j.seppur.2011.04.006

Pawar, S. N., and Edgar, K. J. (2012). Alginate derivatization: a review of chemistry, properties and applications Siddhesh. Biomaterials 33, 3279-3305. doi: 10.1016/j.biomaterials.2012.01.007

Pearse, M. J. (2005). An overview of the use of chemical reagents in mineral processing. Miner. Eng. 18, 139-149. doi: 10.1016/j.mineng.2004.09.015

Rath, R. K., Subramanian, S., and Pradeep, T. (2000). Surface chemical studies on pyrite in the presence of polysaccharide-based flotation depressants. J. Colloid Interface Sci. 229, 82-91. doi: 10.1006/jicis.2000.6990

Reyes-Bozo, L., Escudey, M., Vyhmeister, E., Higueras, P., Godoy-Faúndez, A., Salazar, J. L., et al. (2015). Adsorption of biosolids and their main components on chalcopyrite, molybdenite and pyrite: Zeta potential and FTIR spectroscopy studies. Miner. Eng. 78, 128-135. doi: 10.1016/j.mineng.2015.04.021

Song, S., Zhang, X., Yang, B., and Lopez-Mendoza, A. (2012). Flotation of molybdenite fines as hydrophobic agglomerates. Sep. Purif. Technol. 98, 451-455. doi: 10.1016/j.seppur.2012.06.016

Su, C. H., Kumar, G. V., Adhikary, S., Velusamy, P., Pandian, K., and Anbu, P. (2017). Preparation of cotton fabric using sodium alginate-coated nanoparticles to protect against nosocomial pathogens. Biochem. Eng. J. 117, 28-35. doi: 10.1016/j.bej.2016.10.020

Suyantara, G. P. W., Hirajima, T., Miki, H., Sasaki, K., Yamane, M., Takida, E., et al. (2018). Selective flotation of chalcopyrite and molybdenite using $\mathrm{H} 2 \mathrm{O} 2$ oxidation method with the addition of ferrous sulfate. Miner. Eng. 122, 312-326. doi: 10.1016/j.mineng.2018.02.005

Tian, M., Liu, R., Gao, Z., Chen, P., Han, H., Wang, L., et al. (2018). Activation mechanism of $\mathrm{Fe}$ (III) ions in cassiterite flotation with benzohydroxamic acid collector. Miner. Eng. 119, 31-37. doi: 10.1016/j.mineng.2018.01.011

Wang, B., and Peng, Y. (2014). The effect of saline water on mineral flotation - A critical review. Miner. Eng. 66, 13-24. doi: 10.1016/j.mineng.2014.04.017

Wang, X. (2007). Extraction and application of sodium alginate. J. Chongqing Inst. Technol. Sci. Ed. 21, 124-128. doi: 10.3969/j.issn.1674-8425-B.2007.05.032

Wang, Z., and Yang, H. (2014). Impact of $\mathrm{pH}$ values on viscosity of sodium alginate solution and hydrogen bonds in the system. Mater. Rep. 33, 1289-1292.

Wie, J. M., and Fuerstenau, D. W. (1974). The effect of dextrin on surface properties and the flotation of molybdenite. Int. J. Miner. Process. 1, 17-32. doi: 10.1016/0301-7516(74)90024-6

Yang, B., Wang, D., Wang, T., Zhang, H., Jia, F., and Song, S. (2019). Effect of $\mathrm{Cu} 2+$ and $\mathrm{Fe} 3+$ on the depression of molybdenite in flotation. Miner. Eng. 130, 101-109. doi: 10.1016/j.mineng.2018.10.012

Yin, W. Z., Zhang, L. R., and Xie, F. (2010). Flotation of Xinhua molybdenite using sodium sulfide as modifier. Trans. Nonferrous Met. Soc. 20, 702-706. doi: 10.1016/S1003-6326(09)60201-6

Yin, Z., Sun, W., Hu, Y., Zhang, C., Guan, Q., Liu, R., et al. (2017). Utilization of acetic acid-[(hydrazinylthioxomethyl)thio]-sodium as a novel selective depressant for chalcopyrite in the flotation separation of molybdenite. Sep. Purif. Technol. 179, 248-256. doi: 10.1016/j.seppur.2017.01.049

Yu, C., Wang, M., Dong, X., Shi, Z., Zhang, X., and Lin, Q. (2017). Removal of $\mathrm{Cu}(\mathrm{II})$ from aqueous solution using $\mathrm{Fe} 3 \mathrm{O} 4$-alginate modified biochar microspheres. RSC Adv. 7, 53135-53144. doi: 10.1039/C7RA10185F

Yuan, D., Cadien, K., Liu, Q., and Zeng, H. (2019a). Selective separation of copper-molybdenum sulfides using humic acids. Miner. Eng. 133, 43-46. doi: 10.1016/j.mineng.2019.01.005

Yuan, D., Cadien, K., Liu, Q., and Zeng, H. (2019b). Adsorption characteristics and mechanisms of O-Carboxymethyl chitosan on chalcopyrite and molybdenite. J. Colloid Interface Sci. 552, 659-670. doi: 10.1016/j.jcis.2019.05.023

Zhang, W., and Honaker, R. Q. (2018). Flotation of monazite in the presence of calcite part II: Enhanced separation performance using sodium silicate and EDTA. Miner. Eng. 127, 318-328. doi: 10.1016/j.mineng.2018.01.042 
Zhang, W., Honaker, R. Q., and Groppo, J. G. (2017). Flotation of monazite in the presence of calcite part I: Calcium ion effects on the adsorption of hydroxamic acid. Miner. Eng. 100, 40-48. doi: 10.1016/j.mineng.2016. 09.020

Zhao, Q., Wengang, L., Wei, D., Wang, W., Cui, B., and Wenbao, L. (2018). Effect of copper ions on the flotation separation of chalcopyrite and molybdenite using sodium sulfide as a depressant. Miner. Eng. 115, 44-52. doi: 10.1016/j.mineng.2017.10.008

Zhu, Y., Shen, Y., Wei, D., (2003). Adsorption of sodium alginate to copper ion in disposal water. J. Northeast. Univ. Sci. 24, 589-592.
Conflict of Interest: The authors declare that the research was conducted in the absence of any commercial or financial relationships that could be construed as a potential conflict of interest.

Copyright (c) 2020 Zeng, Ou, Zhang and Zhu. This is an open-access article distributed under the terms of the Creative Commons Attribution License (CC BY). The use, distribution or reproduction in other forums is permitted, provided the original author(s) and the copyright owner(s) are credited and that the original publication in this journal is cited, in accordance with accepted academic practice. No use, distribution or reproduction is permitted which does not comply with these terms. 